Ophthalmic Res 1990;22(suppl 1):I-VI

\title{
Contents, Vol. 22, Supplement 1, 1990
}

\section{Foreword}

Sasaki, K 1

The Multi-Purpose Camera: A New Anterior Eye Segment Analysis System

Sasaki, K..; Sakamoto, Y.; Shibata, T.; Emori, Y 3

Comparison between Topcon SL-45 and SL-45B with Different Correction Methods for

Factors Influencing Scheimpflug Examination

Laser, H.; Berndt, W.; Leyendecker, M.; Kojima, M.; Hockwin, O.; Cheyne, A 9

Reproducibility Studies with the Zeiss SLC System and Animal Cataract Models

Wegener, A.; Laser, H.; Hockwin, 018

New Method of Measuring Nuclear Cataract in Color Scheimpflug Photographs

Kashiwagi, T.; Khu, P.M 24

Imaging Characteristics of Three Cameras Using the Scheimpflug Principle

Kojima, M.; Wegener, A.; Hockwin, $0 \quad 29$

Evaluation of Nuclear Opacification Using a Lens Opacity Meter

Mizuno, T.; Sasaki, K.; Sakamoto, Y 36

Comparison of Retroillumination Images of Crystalline Lenses Taken with Different

Camera Types

Sakamoto, Y.; Rankov, G.; Sasaki, K 41

Classification System for Cataracts. Application by the Japanese Cooperative Cataract

Epidemiology Study Group

Sasaki, K.; Shibata, T.; Obazawa, H.; Fujiwara, T.; Kogure, F.; Obara, Y.; Itoi, M.; Katou, K.;

Akiyama, K.; Okuyama, S 46

Subcapsular Zones of Discontinuity in the Human Lens

Fagerholm, P.; Philipson, B.T.; Lydahl, E 51

Ultraviolet Filter Photography to Demonstrate the Fluorescence of Animal Lenses with

Different Cataract Models

Wegener, A.; Laser, H.; Hockwin, 056

VI Contents

Objective Measurement of Cortical and Subcapsular Opacification in Retroillumination Photographs

Wolfe, J.K.; Chylack, L.T., Jr 62

Subjective (LOCSII) versus Objective (BGS) Measures of Cortical and Subcapsular

Cataracts in Retroillumination Photographs

Khu, P.M.; Kashiwagi, T 68

Comparison between Digital and Analog Image Analysis of Scheimpflug Photographs

Meinel,U.R 71

A New Analysis Method for Cataractous Images Taken by Retroillumination Photo graphy

Miyauchi, A.; Mukai, S.; Sakamoto Y 
Diabetes as Risk Factor of Cataract: Differentiation by Retroillumination Photography and Image Analysis

Yata, K.; Fujiwara, T.; Yamamoto, A.; Ito, K.; Tsuyama, Y 78

Quantitative Chamber Angle Measurement Utilizing Image-Processing Techniques

Shibata, T.; Sasaki, K.; Sakamoto, Y.; Takahashi, N 81

Influence of Certain Drugs on the Densitometry Results of Optic Lens Sections in

Posterior Subcapsular Cataracts

Polunin, G.S 85

Water-Insoluble High-Molecular-Weight and Alpha-Crystallins as the Source of the

Scheimpflug Light Scattering Pattern in the Rat Lens

Bours, J.; Ahrend, M.H.J.; Wegener, A.; Hockwin, 0

90

Changes of Lens Protein Particles during Development and Reversal of Galactose Cata

racts. Study by Laser Scattering Spectroscopy

Kaneda, M.; Majima, Y.; Hattori, H.; Torii, H

Announcement

100

Author Index 101

Subject Index 102 